\title{
The Circulating Visfatin Level Relation to the Severity of Chronic Kidney Disease
}

\author{
Oleksii Korzh*, Anna Titkova, Yana Fylenko \\ Department of General Practice-Family Medicine, Kharkiv Medical Academy of Postgraduate Education, Kharkiv, Ukraine
}

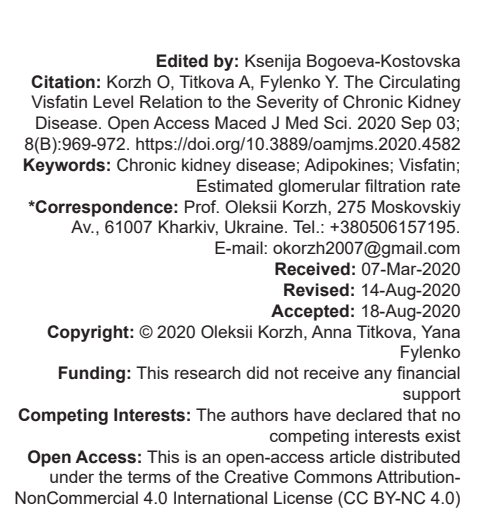

\section{Introduction}

The prevalence of chronic kidney disease (CKD) is high and is increasing in the general population [1], [2]. CKD is associated with an increased risk of end-stage kidney disease, cardiovascular disease (CVD), and premature death. CKD and CVD are closely related to each other and have many common risk factors [3]. Recent studies have shown that adipokines are associated with atherosclerotic CVD [4], but their association with CKD has not been well characterized.

There are different members of adipokines with different roles in health and disease. Sometimes there are conflicting ideas about the effect of adipokines on the pathobiology of kidney disease. There is much debate about the different functions of each adipokine [5]. Most of the previous work on the association between leptin, resistin, adiponectin, and CKD has yielded conflicting results and has been obtained mainly from studies with small sample sizes and/or inconsistent comparisons between patients with CKD and without CKD.

Visfatin is a recently discovered adipocyte hormone. It is predominantly secreted by adipose tissue and enriched with visceral adipose tissue. This hormone is found in the cytoplasm, as well as in the nucleus of cells and has been identified in many tissues and organs, including brain, kidney, lungs, spleen, and testicles, but is mainly expressed in visceral adipose tissue and is activated in some animal obesity models [6], [7].

Visfatin is an endocrine, autocrine, and paracrine peptide with many functions, including enhancing cell proliferation, biosynthesis of monoand dinucleotide nicotinamide, and a hypoglycemic effect. It affects energy metabolism by participating in the synthesis of nicotinamide adenine dinucleotide. The interesting discovery of this protein is that it can induce the production of both anti-inflammatory and pro-inflammatory cytokines [6].

The effect of circulating levels of visfatin on the risk of CKD has rarely been studied in humans. In this study, we examined the association of the serum visfatin level in the patients with CKD and in the control group without CKD.

\section{Methods}

\section{Study participants}

We recruited $101 \mathrm{CKD}$ patients in Kharkiv region from 2017 to 2019 . CKD patients aged $35-75$ years were 
recruited from nephrology and internal medicine clinics through referral physicians by trained research staff in the study area. All eligible CKD patients identified in the recruiting clinics were invited to participate in the study. CKD was defined as an estimated glomerular filtration rate $\left(\right.$ eGFR) $<60 \mathrm{ml} / \mathrm{min} / 1.73 \mathrm{~m}^{2}$ measured twice with 3 months' period apart or the presence of albuminuria ( $\geq 30 \mathrm{mg} / 24 \mathrm{~h}$ ). One hundred and one patients without CKD were enrolled as a control group. The groups matched for age, gender, and body mass index (BMI).

The patients were excluded if they had a history of chronic dialysis, kidney transplants, immunotherapy in the past 6 months, chemotherapy within the past 2 years, and current clinical trial participation that may have an impact on CKD. Additional exclusion criteria were a history of HIV or AIDS and an inability or unwillingness to give informed consent. Controls were recruited through a mass mailing to residents aged $35-75$ years living in the same area according to zip code. The eligibility of controls was assessed by a prescreening telephone interview and the clinic screening visit. Individuals were included if they had no evidence of CKD (eGFR >60 ml/ $\min / 1.73 \mathrm{~m}^{2}$ and no persistent albuminuria) according to the source documents and at the screening visit. Cases and controls were frequency-matched according to age group (10 years), gender, and race to increase the efficiency of patient recruitment and statistical analysis.

The study was conducted in accordance with international standards of bioethics (Council of the European Convention on Human Rights and Biomedicine) and the recommendations of the Committee on Bioethics of the Ministry of Health of Ukraine. All patients signed informed consent to participate in the study. This study was approved by the Ethics Commission of the Kharkiv Medical Academy of Postgraduate Education of the Ministry of Health of Ukraine (Kharkiv, UA).

\section{Measurements}

The standard questionnaire was administered by trained staff at a clinical visit to obtain demographic information, lifestyle risk factors (including cigarette smoking, alcohol drinking, and physical activity), selfreported history of CVD, diabetes, hypercholesterolemia, and hypertension, as well as the use of antihypertensive, lipid-lowering, and antidiabetic medications.

Three blood pressure measurements were obtained at a clinical visit by trained and certified staff according to a common protocol adapted from procedures recommended by the European Society of Hypertension/ European Society of Cardiology 2018 for the treatment of arterial hypertension [8]. The standard mercury sphygmomanometer was used, and one of four cuff sizes (pediatric, regular adult, large, or thigh) was chosen on the basis of the circumference of the participant's arm. Body height and weight were obtained by trained staff and used to calculate BMI and body surface area using Mosteller's formula [(weight in $\mathrm{kg} \times$ height in $\left.\mathrm{cm}) / 3,600)^{1 / 2}\right]$ [9].
The blood samples were collected at 08:00 h after overnight fasting to measure serum visfatin and glucose, serum creatinine ( $\mathrm{SCr}$ ), and cholesterol and triglycerides. eGFR was estimated from $\mathrm{SCr}$, sex, age, and race using the CKD-Epi equation: GFR $=141 \times \min (\mathrm{SCr} / \mathrm{k}, 1) \alpha \times$ $\max (\mathrm{SCr} / \mathrm{k}, 1)^{-1.209} \times 0.993^{\mathrm{Age}} \times 1.018$ (if female) $\times 1.159$ (if black), where $\mathrm{k}$ is 0.7 and 0.9 and $\alpha$ is -0.329 and -0.411 for females and males, respectively [10]. A 24-h urinary sample was collected to measure creatinine and albumin.

Serum cholesterol and triglyceride levels were assayed using an enzymatic procedure on the automatic analyzer. Serum glucose was measured using the hexokinase enzymatic method. SCr was measured using the Roche enzymatic method. Serum visfatin was measured with ELISA assay kits. The assay employs the quantitative sandwich enzyme immunoassay technique and all samples were assayed in duplicate. The intra-assay and inter-assay coefficients of variation were $3.6 \%$ and $5.7 \%$, respectively.

\section{Statistical analysis}

Medians and interquartile ranges for plasma endostatin were calculated for CKD patients and controls and the Mann-Whitney test was used to test differences in the unadjusted medians. Quantile regression was used to obtain adjusted medians (interquartile ranges) and the Wald test was used to test differences in the adjusted medians between CKD patients and controls. Age, gender, race, high school education, current cigarette smoking, weekly alcohol consumption, physical activity ( $\geq$ twice/week), BMI, low-density lipoprotein (LDL) cholesterol, serum glucose, systolic blood pressure, history of hypertension, diabetes, CVD, and medication uses were adjusted in these analyses.

Multivariable linear regression was used to examine the association of eGFR and serum visfatin levels after adjustment for the previously mentioned covariates. The log transformations were used for serum visfatin and urinary albumin levels because they were not normally distributed. In addition, multivariate logistic regression was used to obtain adjusted odds ratios comparing the highest tertile of serum visfatin levels to the lower two tertiles between CKD patients and controls. Serum visfatin tertiles were defined based upon measurements in the control group.

\section{Results}

The general characteristics of study participants by CKD status are presented in Table 1. The patients with CKD were older, less educated, more obese, and less likely to drink alcohol compared to those without CKD. In addition, they were more likely to have a history of CVD, hypertension, diabetes, 
and hypercholesterolemia. Mean BMI, systolic blood pressure, serum glucose, and urinary albumin were significantly higher, while LDL-cholesterol and eGFR were lower in CKD patients compared to controls.

Table 1: Characteristics of the patients with CKD and controls

\begin{tabular}{|c|c|c|c|}
\hline Variables & $\begin{array}{l}\text { CKD patients } \\
(n=101)\end{array}$ & $\begin{array}{l}\text { Non-CKD } \\
(n=101)\end{array}$ & $\begin{array}{l}\mathrm{p} \text { value for } \\
\text { difference }\end{array}$ \\
\hline Age, years & $55.9 \pm 9.9$ & $52.5 \pm 10.0$ & 0.0007 \\
\hline Males, \% & 53.5 & 48.2 & 0.056 \\
\hline High school education, \% & 62.5 & 73.2 & $<0.001$ \\
\hline Current cigarette smoking, \% & 52.8 & 49.5 & 0.30 \\
\hline Weekly alcohol drinking, \% & 26.4 & 55.1 & $<0.0001$ \\
\hline BMI & $32.2 \pm 7.8$ & $28.9 \pm 6.4$ & $<0.0001$ \\
\hline Systolic blood pressure, mmHg & $138.1 \pm 22.3$ & $121.6 \pm 15.4$ & $<0.0001$ \\
\hline Diastolic blood pressure, $\mathrm{mmHg}$ & $78.5 \pm 13.5$ & $76.2 \pm 9.8$ & 0.75 \\
\hline Plasma glucose, mg/dl & $117.8 \pm 48.2$ & $105.6 \pm 29.7$ & $<0.0001$ \\
\hline LDL-cholesterol, mg/dl & $102.6 \pm 48.3$ & $121.4 \pm 32.1$ & $<0.0001$ \\
\hline History of CVD, \% & 39.6 & 8.2 & $<0.0001$ \\
\hline History of hypertension, \% & 85.4 & 26.7 & $<0.0001$ \\
\hline History of diabetes, \% & 44.6 & 6.9 & $<0.0001$ \\
\hline Creatinine, mg/dl & $2.2 \pm 1.4$ & $0.8 \pm 0.3$ & $<0.0001$ \\
\hline eGFR, $\mathrm{ml} / \mathrm{min} / 1.73 \mathrm{~m}^{2}$ & $44.8 \pm 16.5$ & $91.6 \pm 12.7$ & $<0.0001$ \\
\hline Urinary albumin, mg/24 $\mathrm{h}^{\mathrm{a}}$ & $75.6(13.4-421.5)$ & $6.1(4.9-10.9)$ & $<0.0001$ \\
\hline Serum visfatin, $\mathrm{ng} / \mathrm{dl}^{\mathrm{a}}$ & $3.52(2.26-4.78)$ & $1.65(0.82-2.48)$ & $<0.0001$ \\
\hline
\end{tabular}

The distribution of serum visfatin revealed its higher levels in patients with CKD compared to those in controls. The median serum visfatin level and interquartile range were significantly higher in the CKD patients $(3.52 \mathrm{ng} / \mathrm{ml}$, and 2.26-4.78) compared to controls (1.65 ng/ml, 0.82-2.48; $\mathrm{p}<0.0001$ for group difference). After adjustment for age, gender, race, high school education, physical activity, current cigarette smoking, weekly alcohol drinking, BMI, LDL-cholesterol, glucose, systolic blood pressure, and history of CVD the median serum visfatin level remained significantly higher in CKD patients (3.65 ng/ml, and 2.31-4.59) compared to controls $(1.66 \mathrm{ng} / \mathrm{ml}$, and $0.90-2.45$; $p<0.0001$ for group difference).

The scatter plots of plasma visfatin levels versus eGFR and urinary albumin excretion show that serum visfatin was significantly associated with the severity of CKD. The log-transformed serum visfatin levels were significantly and inversely correlated with eGFR ( $r=-0.79, p<0.0001)$ and positively correlated with log-transformed urinary albumin excretion $(r=0.71$, $p<0.0001)$. In the linear regression analyses adjusted for multiple covariables, the log-transformed serum visfatin levels were significantly and inversely related to eGFR and positively related to the log-transformed urinary albumin excretion (Table 2). For example, one standard deviation increase in the log-transformed

Table 2: Multivariable-adjusted regression coefficients $(95 \%$ $\mathrm{Cl}$ ) of one standard deviation higher in log-transformed serum visfatin $(0.01 \mathrm{ng} / \mathrm{dl})$ with eGFR and log-transformed urinary albumin

\begin{tabular}{|c|c|c|c|c|}
\hline \multirow[t]{2}{*}{ Parameter } & \multicolumn{2}{|c|}{ eGFR, $\mathrm{ml} / \mathrm{min} / 1.73 \mathrm{~m}^{2}$} & \multicolumn{2}{|c|}{$\begin{array}{l}\text { Log-transformed } \\
\text { albuminuria } \mathrm{mg} / 24 \mathrm{~h}\end{array}$} \\
\hline & $\begin{array}{l}\text { Effect size } \\
(95 \% \mathrm{Cl})\end{array}$ & $p$ value & $\begin{array}{l}\text { Effect size } \\
(95 \% \mathrm{Cl})\end{array}$ & $p$ value \\
\hline Age-, gender-, race-adjusted & $\begin{array}{l}-18.3 \\
(-20.0,-16.5)\end{array}$ & $<0.0001$ & $\begin{array}{l}1.22 \\
(1.08,1.38)\end{array}$ & $<0.0001$ \\
\hline Multivariable-adjusted ${ }^{1}$ & $\begin{array}{l}-18.6 \\
(-20.3,-16.0)\end{array}$ & $<0.0001$ & $\begin{array}{l}1.09 \\
(1.01,1.25)\end{array}$ & $<0.0001$ \\
\hline Multivariable-adjusted $^{2}$ & $\begin{array}{l}-16.5 \\
(-18.8,-14.3)\end{array}$ & $<0.0001$ & $\begin{array}{l}1.07 \\
(0.96,1.24)\end{array}$ & $<0.0001$ \\
\hline
\end{tabular}

serum visfatin $(0.01 \mathrm{ng} / \mathrm{dl})$ was associated with a decline in eGFR of $-18.6 \mathrm{ml} / \mathrm{min}$ and an increase in urine albumin of $2.95 \mathrm{mg} / 24 \mathrm{~h}$ (after back transformation) in the multivariable models.

In the logistic regression analyses adjusted for age, gender, and race, the participants in the highest tertile ( $\geq 65^{\text {th }}$ percentile) of serum visfatin had a significant 29-fold higher the odds ratio of CKD compared to those in the lower two tertiles (Table 3). After further adjustment for education, cigarette smoking, alcohol drinking, physical activity, BMI, LDL-cholesterol, systolic blood pressure, glucose, and history of CVD the odds ratio of CKD associated with the top tertile of serum visfatin was 22.8fold higher compared to lower serum visfatin. Furthermore, adjustment for the history of hypertension and diabetes did not significantly change the odds ratio estimates.

Table 3: The odds ratio of CKD associated with the top tertile compared with the two lower tertiles of serum visfatin

\begin{tabular}{lll}
\hline Parameter & Odds ratio $(95 \% \mathrm{CI})$ & $\mathrm{p}$ value \\
\hline Age-, gender-, race-adjusted & $29.0(14.8,61.2)$ & $<0.0001$ \\
Multivariable-adjusted' & $22.8(10.7,46.1)$ & $<0.0001$ \\
Multivariable-adjusted ${ }^{2}$ & $21.2(7.9,44.6)$ & $<0.0001$ \\
\hline${ }^{1}$ Adjusted for age, gender, race, high school education, physical activity, current cigarette smoking, \\
weekly alcohol drinking, BMI, LDL-cholesterol, serum glucose, systolic blood pressure, history of CVD. \\
${ }^{2}$ Additionally adjusted for history of hypertension and diabetes. CKD: Chronic kidney disease, Cl: \\
Confidence interval, BMI: Body mass index, LDL: Low-density lipoprotein, CVD: Cardiovascular disease.
\end{tabular}

Confidence interval, BMI: Body mass index, LDL: Low-density lipoprotein, CVD: Cardiovascular disease.

\section{Discussion}

Our study showed that the serum visfatin levels were significantly higher in patients with CKD compared with the control group without CKD. In addition, there was a strong dose-response and the significant relationship between serum visfatin level and CKD severity, assessed by GFR and albuminuria, regardless of established risk factors for CKD, including hypertension, diabetes, and CVD. These results can have important clinical implications. Clear understanding of the Adipobiology of disease can help us to apply Adipokines' approach in pharmacology strategy.

The level of circulating visfatin increases sharply in the patients with CKD and is associated with kidney function and the soluble vascular cell adhesion molecule -1 as a key marker of endothelial damage [3]. In patients, as well as in animals of the 2 type DN model, the level of visfatin is increased. Therefore, visfatin appears to be a pro-inflammatory adipokine in metabolic syndrome and type 2 diabetes [3]. Other studies have shown that administration of visfatin induces the secretion of pro-inflammatory and profibrotic molecules such as type 1 collagen, an inhibitor of plasminogen activator 1 , and transforming growth factor- $\beta$ [11], [12].

Yilmaz et al. found that circulating levels of visfatin were associated with endothelial dysfunction [13]. $\mathrm{Mu}$ et al. reported that the higher level of visfatin is associated with endothelial dysfunction, atherosclerosis, 
and lipid dysregulation in patients with CKD [14]. Axelsson et al. stated that the renal function affects the level of circulating visfatin; however, they were unable to find any significant association between insulin resistance markers and visfatin levels in the patients with CKD [15]. Carrero et al. reported that the patients with CKD with poor appetite have an increased level of visfatin, and it has an unfavorable correlation with triglycerides and fasting serum amino acids [7]. Mahmoud et al. found that with the exception of the significant positive association between visfatin and CKD levels, there was no difference in visfatin concentration in the patients with and without diabetes. In addition, the negative correlation with GFR and the positive correlation with proteinuria have been reported [16].

Several potential limitations of our study should be noted. First of all, the cross-sectional nature of our study makes it difficult to conclude the causal relationship between serum visfatin and the risk of developing CKD. In addition, other adipokines were not measured in our study. However, their association with CKD has been reported in previous studies [3], [4], [10]. Finally, our study has a relatively small sample size. A large prospective cohort study might provide more convincing evidence of the association of serum visfatin with CKD.

\section{Conclusion}

Our study found a strong, independent and dose-response association between the circulating level of visfatin and severity of CKD. However, its pathogenic role in the development and progression of CKD should be determined. Prospective cohort studies and clinical trials are warranted to further examination of the causal relationship between visfatin and the risk of CKD and to develop novel interventions with visfatin which will have the aimed to reduce CKD risk.

\section{References}

1. Levey AS, Coresh J. Chronic kidney disease. Lancet. 2011;379:165-80.

2. Lim CC, Teo BW, Ong PG, Cheung CY, Lim SC, Chow KY, et al. Chronic kidney disease, cardiovascular disease and mortality: A prospective cohort study in a multi-ethnic Asian population. Eur J Prev Cardiol. 2014;22(8):1018-26. https://doi. org/10.1177/2047487314536873

PMid:24857889

3. Rüster C, Wolf G. Adipokines promote chronic kidney disease. Nephrol Dial Transplant. 2013;28(4):iv8-14. https://doi. org/10.1093/ndt/gft191

PMid:24179016

4. Izadi V, Azadbakht L. Specific dietary patterns and concentrations of adiponectin. J Res Med Sci. 2015;20(2):178-84.

PMid:25983773

5. Fasshauer $\mathrm{M}$, Blüher $\mathrm{M}$. Adipokines in health and disease Trends Pharmacol Sci. 2015;36(7):461-70.

PMid:26022934

6. Moschen AR, Kaser A, Enrich B, Mosheimer B, Theurl M, Niederegger $\mathrm{H}$, et al. Visfatin, an adipocytokine with proinflammatory and immunomodulating properties. J Immunol. 2007;178(3):1748-58. https://doi.org/10.4049/ jimmunol.178.3.1748

PMid:17237424

7. Carrero JJ, Witasp A, Stenvinkel P, Qureshi AR, Heimbürger O, Bárány $\mathrm{P}$, et al. Visfatin is increased in chronic kidney disease patients with poor appetite and correlates negatively with fasting serum amino acids and triglyceride levels. Nephrol Dial Transplant. 2010;25(3):901-6. https://doi.org/10.1093/ndt/gfp587

PMid:19948877

8. Williams B, Mancia G, Spiering W, Rosei EA, Azizi M, Burnier M, et al. $2018 \mathrm{ESC} / \mathrm{ESH}$ guidelines for the management of arterial hypertension: The task force for the management of arterial hypertension of the European society of cardiology (ESC) and the European society of hypertension (ESH). Eur Heart J. 2018;39(33):3021-104. https://doi.org/10.1201/b17072-61

9. Verbraecken J, Van de Heyning P, De Backer W, Van Gaal L. Body surface area in normal-weight, overweight, and obese adults. A comparison study. Metabolism. 2006;55(4):515-24. https://doi.org/10.1016/j.metabol.2005.11.004 PMid:16546483

10. LeveyAS, Cores J, Greene T, LesleyAS, Zhang Y, Hendrickson S, et al, The Chronic Kidney Epidemiology Collaboration. Using standardized serum keratinize values in the modification of diet in renal disease study equation for estimating glomerular filtration rate. Ann Intern Med. 2006;145(4):247-54. https://doi. org/10.7326/0003-4819-145-4-200608150-00004

PMid: 16908915

11. Kang YS, Song HK, Lee MH, Ko GJ, Han JY, Han SY, et al. Visfatin is upregulated in Type-2 diabetic rats and targets renal cells. Kidney Int. 2010;78(2):170-81. https://doi.org/10.1038/ ki.2010.98

PMid:20375985

12. Song HK, Lee MH, Kim BK, Park YG, Ko GJ, Kang YS, et al. Visfatin: A new player in mesangial cell physiology and diabetic nephropathy. Am J Physiol Renal Physiol. 2008;295(5):F148594. https://doi.org/10.1152/ajprenal.90231.2008 PMid:18768589

13. Yilmaz MI, Saglam M, Carrero JJ, Qureshi AR, Caglar K, Eyileten $\mathrm{T}$, et al. Serum visfatin concentration and endothelial dysfunction in chronic kidney disease. Nephrol Dial Transplant. 2008;23(3):959-65. https://doi.org/10.1093/ndt/gfm727 PMid: 17984105

14. Mu J, Feng B, Ye Z, Yuan F, Zeng W, Luo Z, et al. Visfatin is related to lipid dysregulation, endothelial dysfunction and atherosclerosis in patients with chronic kidney disease. J Nephrol. 2011;24(2):177-84. https://doi.org/10.5301/jn.2010.3488 PMid:20602330

15. Axelsson J, Witasp A, Carrero JJ, Qureshi AR, Suliman ME, Heimbürger $O$, et al. Circulating levels of visfatin/pre-B-cell colony-enhancing factor 1 in relation to genotype, GFR, body composition, and survival in patients with CKD. Am J Kidney Dis. 2007;49(2):237-44. https://doi.org/10.1053/j.ajkd.2006.11.021

16. Mahmood N, Junejo AM, Jamal Q, Awan R. Association of visfatin with chronic kidney disease in a cohort of patients with and without diabetes. J Pak Med Assoc. 2010;60(11):922-6.

PMid:21375196 